\title{
Analytical and Experimental Investigation of Ice Melting in Power Line Ground Wires
}

\author{
Tamas Bagi ${ }^{1 *}$ \\ ${ }^{1}$ Department of Safety Science, Doctoral School on Safety and Security Sciences, University of Óbuda, H-1034 Budapest, \\ 96/B Bécsi Street, Hungary \\ * Corresponding author, e-mail: bagi.tamas@elinor.hu
}

Received: 18 November 2019, Accepted: 21 February 2020, Published online: 10 March 2020

\begin{abstract}
The present case study, using computer modeling technology, is to investigate the process of ice melting (de-icing) on iced ground wires due to current flowing through the ground wire. Using the AC model, the time course of heating of the given ground wire has been determined, and treating the results as input to the thermal model, the ice melting process has also been investigated by finite element thermal analysis. After comparing the elements by computer analysis to laboratory measurements, the results obtained were validated with numerical analysis.
\end{abstract}

Keywords

ice melting, de-icing, FE thermal analysis, electric warming, electric measurements, coupled thermal-electric FE analysis

\section{Introduction}

Extreme weather phenomena due to climate change have been gained attention today threaten the safe operation of the electricity system and pose a risk to life and property security. Primarily, the icing has caused significant damage to several sections of the transmission and distribution network in the recent years. In particular, many damages (wire rupture, tower collapse) occurred in 2013 and 2014. The ground wire is primarily exposed to icing. The development of possible solutions is facilitated by computer modeling and related measurements carried out in the high-voltage electrical laboratory of the Department of Electric Power Engineering of the Budapest University of Technology and Economics (BME). During the tests the heating of $95 / 55 \mathrm{~mm}^{2}$ ground wires were tested under different operating conditions depending on load current and icing $[1,2]$.

\section{Materials, method and part results}

\subsection{Electric model}

The initial data needed for computer simulation and ice-melting experiments were to test the heating of the wires, so it was necessary to perform these experiments first. These experimental tests dealt with the computer stimulation of wire heating (using the laws of Alternating
Current Resistance, Eddy Current and Hysteresis Loss of the Wires [3-5]) and, in addition, electrical measurements were taken with the same parameters.

\subsubsection{Testing of wire warming without icing}

According to MSZ EN 50182:2001 standard [6], the load capacity of $95 / 55 \mathrm{ACSR}$ wire at $100^{\circ} \mathrm{C}$ in summer is $405 \mathrm{~A}$, while in winter $490 \mathrm{~A}$. In a view of this, wires with current of 200 A were investigated, meanwhile the time course of temperature and the temperature at constant load were also observed. During the measurement, the temperature data provided by the two surface temperature sensors was manually recorded and checked with a thermal imaging camera ( 2 single channel multimeters and 1 thermal imaging camera; see in Fig. 1 and Fig. 2).

\subsubsection{Investigation of wire warming in icy conditions}

Two methods were carried out to produce the winter icy condition of wires. For both methods 50-60 cm long ACSR $95 / 55 \mathrm{~mm}^{2}$ wires had been prepared. In the first method the wire was placed in dry ice (carbon dioxide) container provided by Messer Hungarogáz Ltd. After cooling the wire for 10-15 minutes, water was being sprayed on it, thus forming the necessary ice layer gradually (see in Fig. 3). 


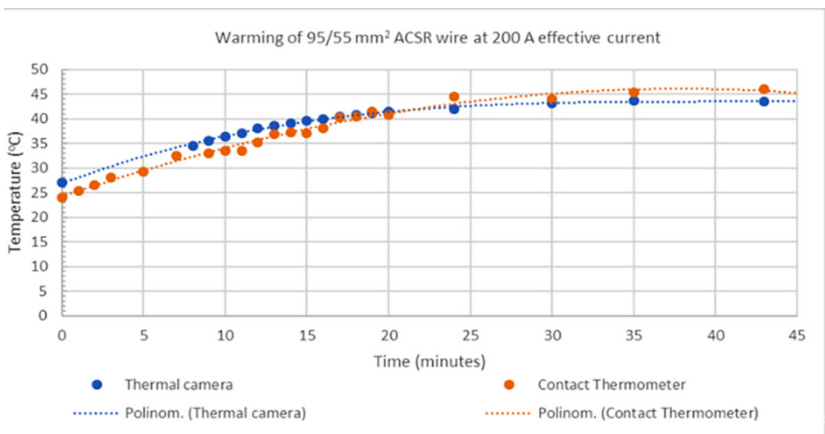

Fig. 1 Measurement - Warming of $95 / 55 \mathrm{~mm}^{2}$ ACSR wire at $200 \mathrm{~A}$ effective current

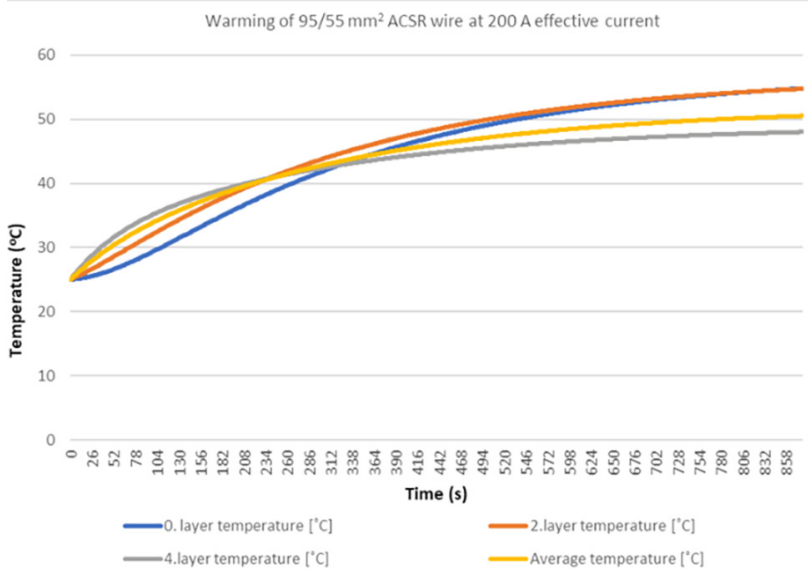

Fig. 2 Simulation - Warming of $95 / 55 \mathrm{~mm}^{2}$ ACSR wire at $200 \mathrm{~A}$ effective current

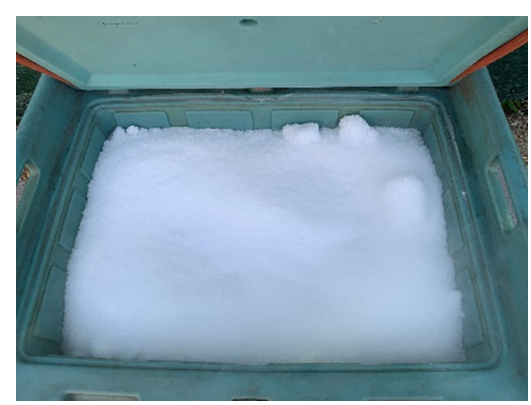

Fig. 3 Thermal insulated container with dry ice

The growth rate of the ice layer (ice stratum) is approximately $1 \mathrm{~cm}$ in diameter in 1 hour (see in Fig. 4). The aim of the experiment was to form ice with the same thickness as of the wire diameter. This ice formation, of course, is not uniform in thickness, as in reality (see in Fig. 5).

In the second method concentric ice sheet was to produce on the wire used in the simplified finite element model carried out previously. For this again $50-60 \mathrm{~cm}$ wire pieces and $63 \mathrm{~mm}$ and $110 \mathrm{~mm}$ KPE type plastic pipes were used in the following layout (see arrangement in Fig. 6).

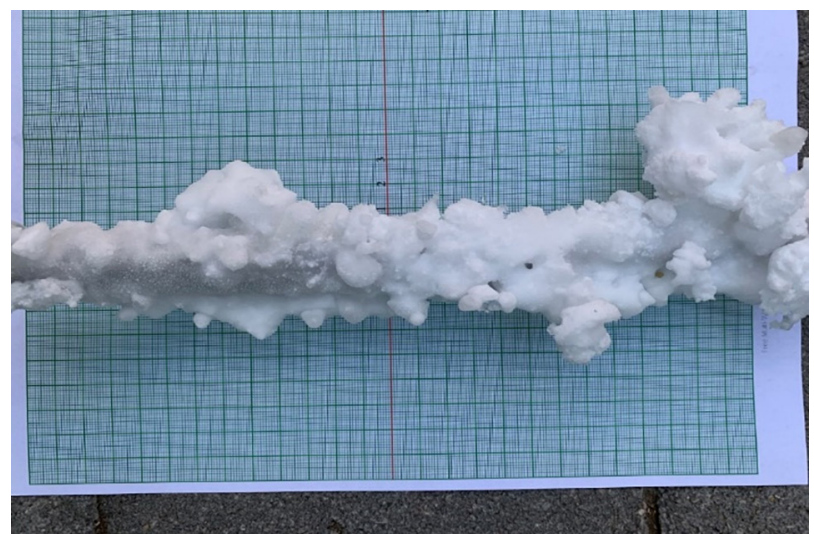

Fig. 4 Ripped iced wire

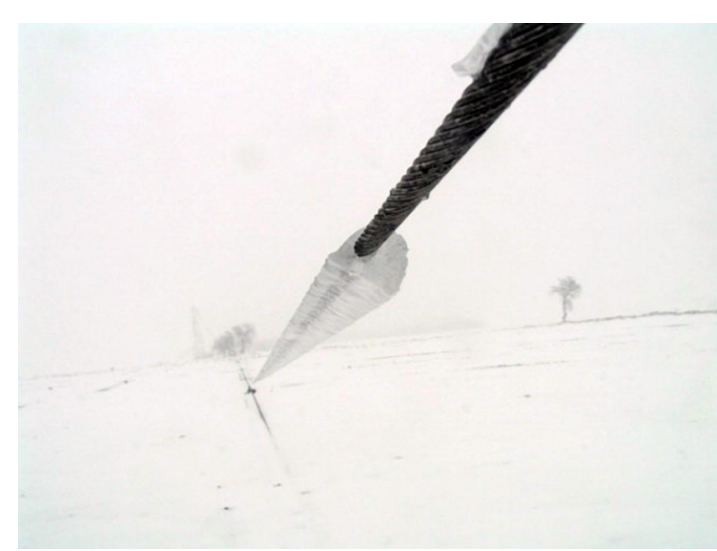

Fig. 5 Iced wires in the experiment

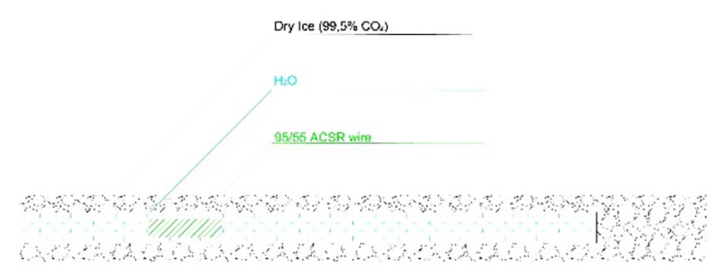

Fig. 6 Second Method layout

The wire was placed in the $63 \mathrm{~mm} \mathrm{KPE}$ tube, it was filled with water then sealed. After that this sealed tube was put in a heat insulated container and sprinkled with dry ice. An hour later, after checking, it could be seen that the water in the tube had been frozen and formed concentric ice. Unfortunately, this experiment was not successful for the time being, as dry ice could not sufficiently cool the liquid, and the $\mathrm{CO}_{2}$ generated by sublimation could leave from the sealed system with difficulty. Improving the experimental equipment is still in progress [7].

The wire with ice was heated under laboratory conditions, and the process was measured with a thermal camera and a contact thermometer (see in Fig. 7). 


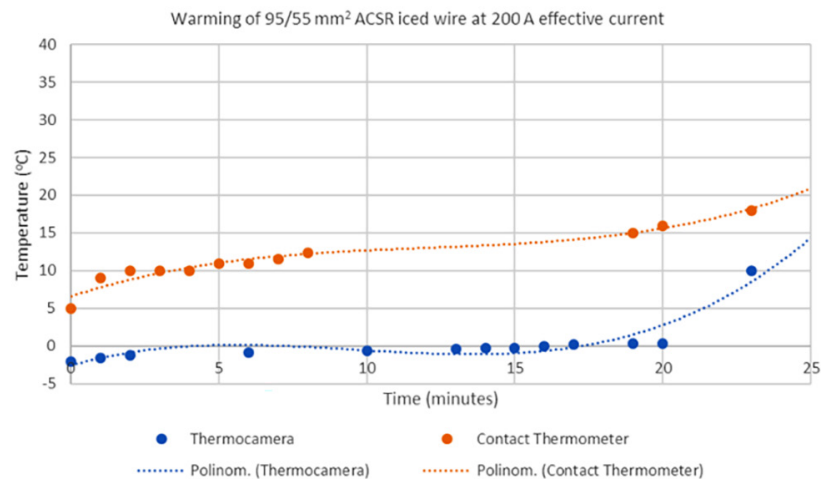

Fig. 7 Warming of 95/55 $\mathrm{mm}^{2}$ ACSR iced wire at 200 A effective current

\subsection{Simplified FEA simulation of de-icing of an ground wire}

A simplified simulation was created to check the warming up and de-icing procedure of an iced cable. Two different FEA models were preformed according to arrangement of the real measurements. The first model consisted of a pure cable with a length of $2500 \mathrm{~mm}$. The dimensions (and the simplified structure) of the cross-section was according to the details of the 95/55 ACSR wire). The aim of this model was to compare the warming up procedure with the real measurement detailed in Fig. 7.

Also a second, extended model was created which contained the simplified ice according to the arrangement of the laboratory test. As it could be seen the diameter of the ice was approx. twice of the diameter of the cable (the equivalent outer diameter of the ice was $96 \mathrm{~mm}$. The length of the ice was $625 \mathrm{~mm}$. Material properties were taken from the literature to construct the thermal model [8-10].

The structure of the two different models can be seen in the Fig. 8.

\subsubsection{The properties of the FEA model}

Coupled transient thermal-electric analyses were performed, using ANSYS 2019R2 Workbench software to take a closer look inside of the de-icing and warming-up procedure. During the simulation 20-node hexahedron elements were used. The element size was $4 \mathrm{~mm}$ on the cable and also $4 \mathrm{~mm}$ on the ice. The type of contact between the two bodies was bounded (using MPC formulation) [11, 12].

200 A current was applied onto the outer ring (one side) of the cable (onto the aluminum layer) (with $0 \mathrm{~V}$ voltage on the other side) which provided the heat for de-icing. The environment temperature was $22{ }^{\circ} \mathrm{C}$ and the temperature of the ice (and the cable section which is under the ice) was to $-5{ }^{\circ} \mathrm{C}$. To model the radiative cooling and heating

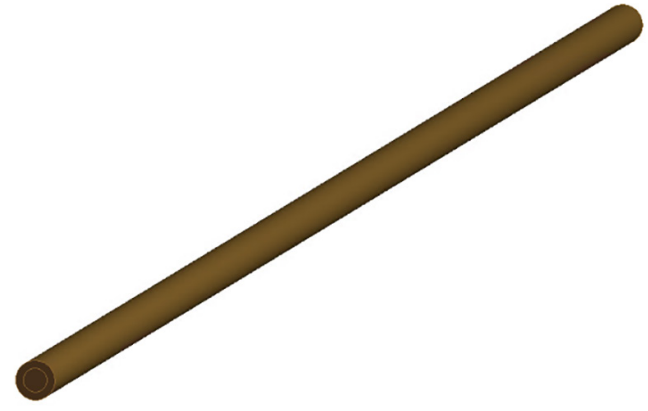

(a)

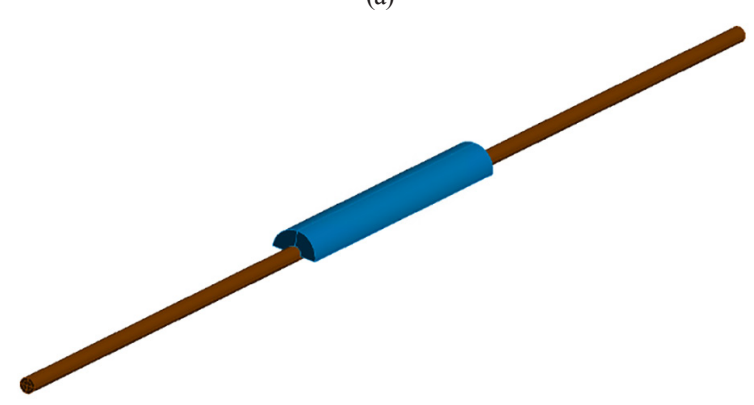

(b)

Fig. 8 The structure of the geometry models (a) cable model (b) cable model with ice

effect of the environment the thermal radiation was set to 0.09 and thermal convection was $0.5 \mathrm{~W} / \mathrm{m}^{2}$ during the analyses. The values were constant during the analysis.

The structure of the cable was simplified and assumed as a simple rod (with two layers according to the thickness of the aluminum cover and steel core and the ice was a half ring. The equivalent thermal material properties of the composite cable and the ice are listed in Table 1. The material properties of the cable are according to the standard of the cable type [13].

\subsubsection{Results}

The Fig. 9 shows the warming-up procedure of the cable after current heating using coupled transient thermal-electric simulation (without ice). As it can be seen the results match with the results of the measurements (FEA: $44.5^{\circ} \mathrm{C}$, laboratory measurement $\sim 45^{\circ} \mathrm{C}$ ), the parameters of the $\mathrm{FE}$ model are acceptable for further investigations.

The initial weight of the ice was approximately 4000 g. During the simplified analysis uniform melting of the ice was assumed. However this approach neglects the non-uniform real melting procedure, gives a good approximation how much time is needed to heat the cable to reach full melting of the covering ice. The simplified criterion was the weight loss when the "ice" temperature 
Table 1 Equivalent material properties of the cable

Equivalent material properties of the cable

\begin{tabular}{|c|c|}
\hline \multicolumn{2}{|c|}{ Equivalent material properties of the cable } \\
\hline Temperature $\left({ }^{\circ} \mathrm{C}\right)$ & Thermal conductivity $(\mathrm{W} / \mathrm{mK})$ \\
\hline-100 & 114 \\
\hline 0 & 144 \\
\hline 100 & 165 \\
\hline \multicolumn{2}{|c|}{ Specific heat $(\mathrm{J} / \mathrm{kgK}): 875$} \\
\hline Temperature $\left({ }^{\circ} \mathrm{C}\right)$ & Isotropic Resistivity (ohm m) \\
\hline-10 & $3.023 \mathrm{e}-8$ \\
\hline 0 & $3.253 \mathrm{e}^{-8}$ \\
\hline 20 & $3.46 \mathrm{e}-8$ \\
\hline 100 & $4.43 \mathrm{e}-8$ \\
\hline \multicolumn{2}{|c|}{ Ice } \\
\hline Temperature $\left({ }^{\circ} \mathrm{C}\right)$ & Thermal conductivity $\mathrm{W} / \mathrm{mK}$ ) \\
\hline-20 & 2.33 \\
\hline 0 & 0.561 \\
\hline 5 & 0.5706 \\
\hline 10 & 0.58 \\
\hline 15 & 0.5894 \\
\hline 20 & 0.5984 \\
\hline 25 & 0.6072 \\
\hline 30 & 0.6155 \\
\hline 35 & 0.6233 \\
\hline 40 & 0.6306 \\
\hline 45 & 0.6373 \\
\hline 50 & 0.6436 \\
\hline 60 & 0.6544 \\
\hline \multicolumn{2}{|c|}{ Specific heat $(\mathrm{J} / \mathrm{kgK}): 4211$} \\
\hline
\end{tabular}

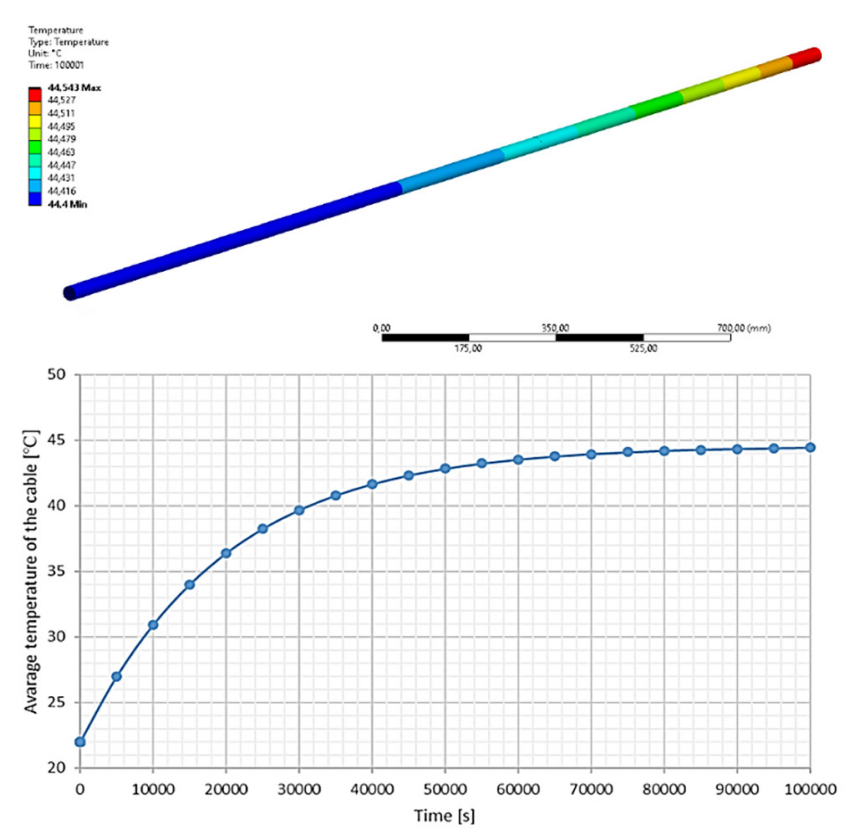

Fig. 9 The final temperature and the warming up procedure of the cable after current heating during the FEA reaches positive ${ }^{\circ} \mathrm{C}$ values. Weight was being lost because of the warming procedure in function of time that can be seen in Fig. 10.

The heating up procedure visually can be seen in Fig. 11.

Examining the warming-up curve it can stated that the total melting will occur approximately $5000 \mathrm{~s}$ after the heating procedure started (the curve shows one outer middle point's temperature on the surface of the ice), see in Fig. 12.

Comparing the results with the laboratory measurements, it can be seen that the trends of heating of the cable and ice in the case of the FEA are like the real measurements. This means, using this simplified model structure in the future, the real de-icing procedure in real environment can be calculated without other laboratory or preliminary field tests furthermore the extra load of the ice and relaxation of the cable after de-icing can also be simulated using coupled thermal-electric-mechanical simulation(s).

\section{Conclusion}

The results obtained from each measurement and computer simulation are in good agreement. The smaller differences are due to measurement uncertainty and simplification of modeling. The process of thawing ice layers is well illustrated by the thermal analysis, and further refining of the thermal model is planned in order to obtain even more accurate results.

\section{Acknowledgement}

Hereby I would like to thank Budapest University of Technology and Economics - Department of Electric Power Engineering that ensured all the necessary conditions to execute the laboratory measurements; Dr P. T. Zwierczyk who provided great support with his expertise and useful remarks/advise to develop the "Ansys" model

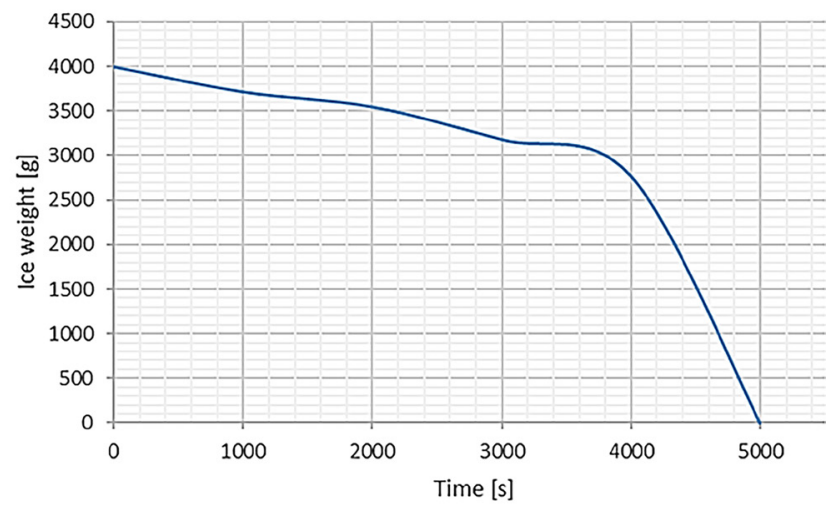

Fig. 10 Weight of the ice in function of time 

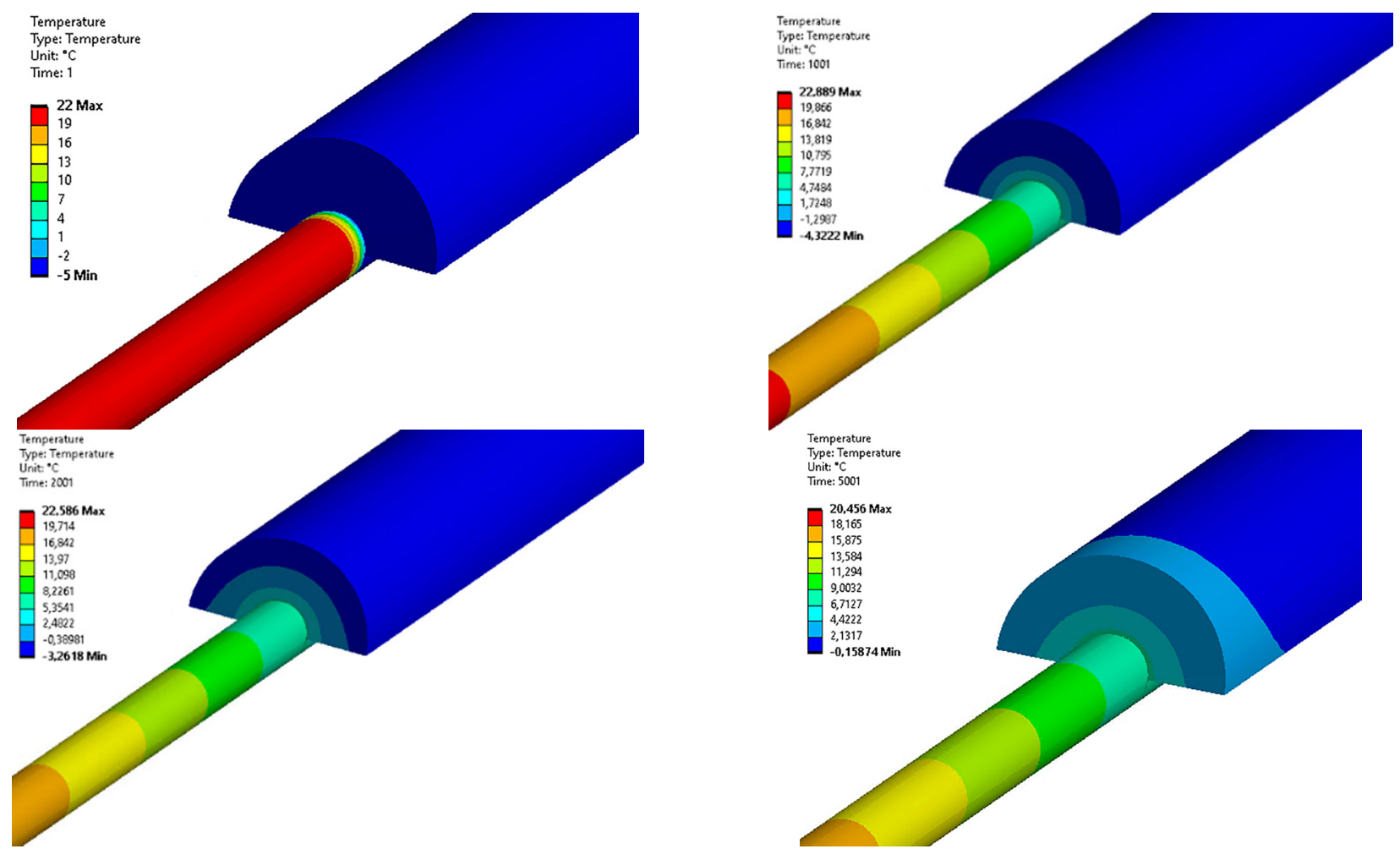

Fig. 11 Visualization of the ice warming up procedure

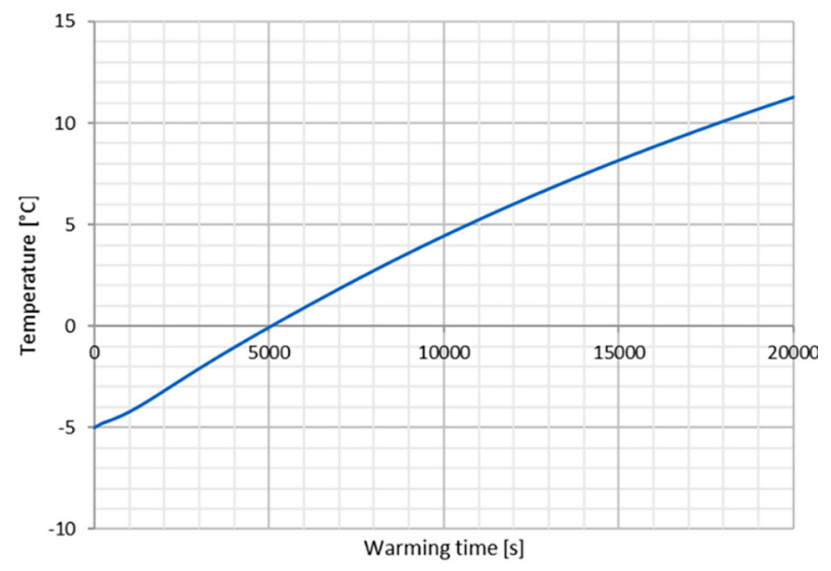

Fig. 12 Warming up procedure of the ice

\section{References}

[1] Bagi, T., Morva, G. "A magyarországi átviteli hálózatokon tapasztalt jegesedési problémák vizsgálata" (The Analysis of Issues Related to Ice Formation Experienced on Hungarian Power Transmission Lines), In: XXXIII. Cando Conference, Budapest, Hungary, 2017, pp. 78-79. (in Hungarian)

[2] Hungarian Standards Institution "MSZ 149-2:1983 Erősáramú vezetéksodronyok. Alumínium vezetéksodrony (MSZ 149-2:1983 Heavy current stranded conductors. Aluminum stranded conductor)", Hungarian Standards Institution, Budapest, Hungary, 1983. (in Hungarian)

[3] Bagi, T. "A method presented by measurements to prevent harmful effects of icing forming on ground wires of high-voltage transmission lines", In: 34th Danubia-Adria Symposium on Advances in Experimental Mechanics, Trieste, Italy, 2017, pp. 1-3.

[4] Bagi, T. "Examination of a Typical High Voltage Phase Conductor Under Various Operating and Load Conditions", In: 6th International Scientific Conference on Advances in Mechanical Engineering (ISCAME 2018), Debrecen, Hungary, 2018, pp. 7-8.

[5] Simonyi, K., Zombory, L. "Elméleti Villamosságtan" (Theoretical Electrical Science), Müszaki Könyvkiadó, Budapest, Hungary, 2000. (in Hungarian) 
[6] Hungarian Standards Institution "MSZ EN 50182:2001 Conductors for overhead lines. Round wire concentric lay stranded conductors", Hungarian Standards Institution, Budapest, Hungary, 2001.

[7] Bagi, T. "Warming and Load Testing of Steel Ground Wires in Laboratory: Simplified Load Testing", In: 2018 International IEEE Conference and Workshop in Óbuda on Electrical and Power Engineering (CANDO-EPE), Budapest, Hungary, 2018, pp. 000283-000288.

https://doi.org/10.1109/CANDO-EPE.2018.8601131

[8] Kondepudi, D., Prigogine, I. "Modern Thermodynamics: From Heat Engines to Dissipative Structures", Wiley-Blackwell, Chichester, UK, 2014. https://doi.org/10.1002/9781118698723

[9] Petrenko, V. F. "Electrical Properties of Ice", U.S. Army Corps of Engineers, Cold Regions Research and Engineering Laboratory, Hanover, NH, USA, Rep. 93-20, 1993.
[10] The Engineering ToolBox "Ice - Thermal Properties: Thermal and thermodynamic properties of ice - density, thermal conductivity and specific heat at temperatures from 0 to $-100{ }^{\circ} \mathrm{C}$, [online] Available at: https://www.engineeringtoolbox.com/ice-thermal-properties-d_576.html [Accessed: 16 October 2019]

[11] ANSYS, Inc. "ANSYS 2019R2" [computer program] Available at: https://www.ansys.com/products [Accessed: 05 July 2019]

[12] Zwierczyk, P. T., Váradi, K. "Thermal Stress Analysis of a Railway Wheel in Sliding-Rolling Motion", Journal of Tribology, 136(3), Article number: 031401, 2014. https://doi.org/10.1115/1.4027544

[13] Callister, W. D. "Materials Science and Engineering: An Introduction", John Wiley and Sons, New York, NY, USA, 1994. 